\title{
Salesman killed when forklift falls off truck loading ramp
}

\section{SUMMARY}

On June 4, 2007, a 37-year-old forklift salesman was crushed, and died 2 days later, after a forklift he was delivering for a customer fell off the dock plate between a flatbed truck and a loading dock. The truck had been backed up to the loading dock, the parking brake set, and the transmission placed in neutral. However, the truck wheels were not blocked against motion. The salesman initially operated the forklift to release tension on the winch line as the truck driver removed the binding chains. As the truck driver went to store the binding chains, the salesman backed the forklift off the bed of the truck. The truck bed was 9 inches

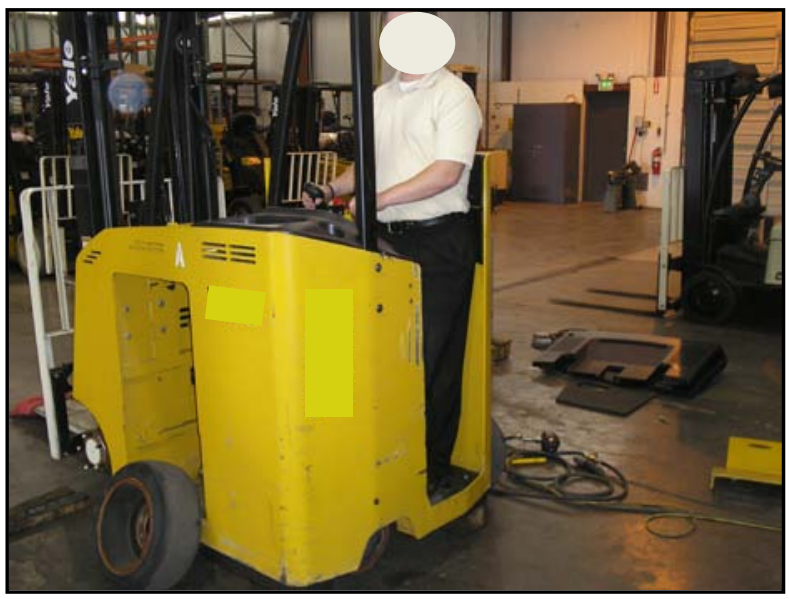

The actual forklift in this incident (with identifying images masked out) was a stand-up model for warehouse work. below the loading dock, and the dock plate connecting the truck to the dock was set at an incline. The drive wheels were on the front of the forklift (to the rear in this instance), and as the salesman accelerated to go up the incline, the drive wheels on the bed of the truck pushed the truck away from the dock. The dock plate slipped off the truck bed and the forklift fell 4 feet to the ground. The victim was crushed between the forklift and the loading dock.

\section{CAUSE OF DEATH: Blunt chest trauma}

\section{RECOMMENDATIONS}

- Before loading or unloading operations, completely block the truck and trailer against motion.

- Employers must train operators of powered industrial trucks in safe operating procedures and hazards associated with particular operations, such as loading and unloading from transport vehicles.

- Employees need to clearly communicate with coworkers when working together on or near moving machinery. 


\section{INTRODUCTION}

On June 4, 2007, a 37-year-old salesman was fatally injured when the electric stand-up forklift he was operating fell off the rear of a flatbed truck, pinning him between the loading dock and the forklift. OR-FACE was notified of the incident on June 7, 2007. Telephone interviews were conducted with the employer. This report is based on the OR-FACE interview information and reports from Oregon OSHA, the medical examiner, and news media.

The employer was a full-service material handling firm, providing fleet management, sales, rentals, and service of new and used powered industrial trucks. The firm was in business for 14 years, with nine locations and 210 workers in three western states. There were eight workers at the Oregon location where the victim worked.

The firm provided certified forklift operator training for employees. The salesman worked as a sales/accounts manager for this employer for $2 \frac{1}{2}$ years. He had 10 years of experience as a forklift operator, and had been recertified 10 months before the incident. His work duties included demonstrating lift trucks to clients. He was the main person responsible for deliveries.

The firm contracted with local trucking/towing firms to make forklift deliveries, and regularly used the towing company involved in this incident, several times a week. The truck driver was not one of the usual drivers; the salesman and driver had worked together perhaps a dozen times in the past 2 years. The driver had worked for the towing company for 2 years, and regularly drove the truck involved in the incident a few times a week.

\section{INVESTIGATION}

The forklift salesman was delivering a newer three-wheel stand-up electrical forklift to a local company for a sales trial. A tow-truck operator was contacted to deliver the forklift on a flatbed truck to the client's warehouse loading dock. The salesman rode with the truck driver to the warehouse to demonstrate the forklift to employees at the warehouse.

The truck driver backed the flatbed up to the loading dock until it stopped against the dock. The dock was about 4 feet high, and about 9 inches higher than the loaded truck bed. The forklift weighed nearly 5 tons, which depressed the truck bed by 7 inches. The hinged dock plate lowered onto the bed of the truck extended out only 15 inches, so when in place, it sloped down to the truck bed at an angle of roughly 37 degrees. The back frame of the forklift had a clearance of only 4 inches and could clear a slope of 44 degrees.

The truck driver set the parking brake, put the transmission into neutral, and left the engine running to operate the hydraulic winch that controlled the line securing the forklift. No chocks were set under the truck's wheels or other measures taken to block the truck against motion before working to unfasten the forklift. The salesman climbed to the truck bed to operate the forklift to relax tension on the winch line, while the driver engaged the winch at the back of the truck to slacken and remove the tie downs and bindings. The driver returned toward the cab to store the bindings. While his back was turned, the salesman immediately started to back the forklift up the ramp to the loading dock. 
The weight of the forklift moving toward the rear of the truck bed, behind the rear axle, lowered the bed further and increased the angle of the steel dock plate. The salesman accelerated to back the forklift up the incline. The drive wheels on the front of the forklift were still on the truck bed, and the resistance against the forklift caused the drive wheels to push the truck away from the loading dock. The driver felt the movement and turned to yell "Stop"; but by then the forklift was already falling off the back of the truck as the dock plate separated from the truck bed. The truck rolled an estimated 15 feet.

The salesman fell off the forklift onto the concrete and was crushed between the forks and the loading dock. The truck driver yelled for help and several warehouse workers responded and called for emergency response. The victim was transported to the hospital, where he died 2 days later.

\section{RECOMMENDATIONS/DISCUSSION}

\section{Recommendation \#1. Before loading or unloading operations, completely block the truck and trailer against motion.}

Wheel chocks or other measures to securely block transport vehicles against motion should be in place before loading or unloading. Do not depend solely on a parking brake to prevent vehicle movement. In addition, the 5-ton weight of this forklift required special precautions. Additional measures could have included securing the loading dock plate to the truck, and using fixed jacks to raise the load off the wheels. Most of all, this incident emphasizes the importance of following a predetermined protocol sequentially, i.e., completely secure the vehicle against motion before releasing or moving the load.

\section{Recommendation \#2. Employers must train operators of powered industrial trucks in safe operating procedures and hazards associated with particular operations, such as loading and unloading from transport vehicles.}

This employer in this incident trained and certified forklift operators, but the victim had no training and little experience with unloading a forklift directly onto a loading dock. The forklift in this case was the first of its type to be sold by the employer at this location. The forklift was loaded onto the truck from the ground by winching it up a ramp, and unloading usually occurred by a similar procedure from the truck to the ground.

Machine operators must read and follow the manufacturer's operating manual for each specific machine used. This incident emphasizes, however, that generic operator training, certification, and review may not be sufficient to transfer critical safety information. The manufacturer's operating manual provides a basic reference that should be adapted and expanded by the employer to particular operational settings for "competency-based" training. Operating procedures must be defined under actual conditions of use, including delivery and maintenance. Actual performance and practice are necessary to make sure the trainee acquires the necessary knowledge. 


\section{Recommendation \#3. Workers need to clearly communicate with coworkers when working together on or near moving machinery.}

This incident emphasizes the importance of communication when two or more workers are performing work on or near moving machinery, or where other hazardous conditions are present. Communication as a safety factor is observed in a many work situations, especially in relation to mobile machinery and persons nearby on the ground. When working around mobile machinery, a worker should inform nearby coworkers of intended actions. Communication is particularly important if the coworker is not visible or has attention directed elsewhere. Better communication in this incident may have allowed the two workers to coordinate their activities and possibly prevent the unexpected vehicle movement.

The concept of "crew resource management" in aviation, concerned with managing errors in flight, is a relevant model for industry. Based on the idea that the training and skills of one competent person may not be sufficient to prevent a critical error in performing a task, crew resource management emphasizes the importance of encouraging any member of a team to speak up to question a situation. The procedure requires special attention, because communication among team members is often obstructed by concerns for hierarchy, personal attitudes, or possibly in this case, unfamiliarity with coworkers. Each company and individual worker needs to find appropriate ways in critical situations to step outside established roles and personalize communication. Clear communication is particularly important with a new partner or team member, or when workers from different companies work together on a task.

\section{REFERENCES}

Center for Research on Occupational and Environmental Toxicology. Powered industrial trucks (Forklifts). Online resource: www.croetweb.com/links.cfm?subtopicID=373

Helmreich, R.L., Merritt, A.C., \& Wilhelm, J.A. (1999). "The evolution of crew resource management training in commercial aviation.” International Journal of Aviation Psychology, 9(1), 19-32. Available online: http://homepage.psy.utexas.edu/homepage/group/HelmreichLAB/Publications/pubfiles/Pub235.pdf

National Institute for Occupational Safety and Health. (2001). Preventing injuries and deaths of workers who operate or work near forklifts [Pub 2001-109]. Available online in English and Spanish: www.cdc.gov/niosh/2001-109.html

Oregon OSHA. Powered industrial trucks. Online resource:

www.cbs.state.or.us/external/osha/subjects/powered_industrial_trucks.html.

Oregon OSHA. Industrial truck operator training guide. Available online:

www.cbs.state.or.us/external/osha/pdf/pubs/forklift.pdf 
Sullivan, R.S. (1995). The competency-based approach to training. U.S. Agency for International Development. Available online:

http://www.reproline.jhu.edu/english/6read/6training/cbt/cbt.htm

\section{FOR MORE INFORMATION}

\section{OR-FACE/CROET L606}

Oregon Health \& Science University

3181 SW Sam Jackson Park Rd

Portland OR 97239-3098

Phone 503-494-2281

Email: orface@ohsu.edu

Website: www.ohsu.edu/croet/face/

Oregon Fatality Assessment and Control Evaluation (OR-FACE) is a project of the Center for Research on Occupational and Environmental Toxicology (CROET) at Oregon Health \& Science University (OHSU). OR-FACE is supported by a cooperative agreement with the National Institute for Occupational Safety and Health (NIOSH), Division of Safety Research (U60/OH0O8324), through the Oregon Worker IIIness and Injury Prevention Program (OWIIPP), Oregon Public Health Division.

OR-FACE reports are for information, research, or occupational injury control only. Safety and health practices may have changed since the investigation was conducted and the report was completed. Persons needing regulatory compliance information should consult the appropriate regulatory agency. 